\title{
Erratum to: The Role of the Middle Class in Distributional Outcomes: Chile and South Korea
}

\section{Judith Teichman}

Published online: 24 December 2014

(C) Springer Science+Business Media New York 2014

\section{Erratum to: St Comp Int Dev \\ DOI 10.1007/s12116-014-9166-y}

The original abstract for the article stated, "While equality has been historically low in South Korea, it has been high in Chile throughout the twentieth century, increasing substantially during the period of military rule." It should read, "While inequality has been historically low in South Korea, it has been high in Chile throughout the twentieth century, increasing substantially during the period of military rule."

The online version of the original article can be found at http://dx.doi.org/10.1007/s12116-014-9166-y.

J. Teichman $(\bowtie)$

Munk School of Global Affairs, University of Toronto, 1 Devonshire Place, Toronto, Ontario M5S 3K7, Canada

e-mail: judith.teichman@utoronto.ca 